
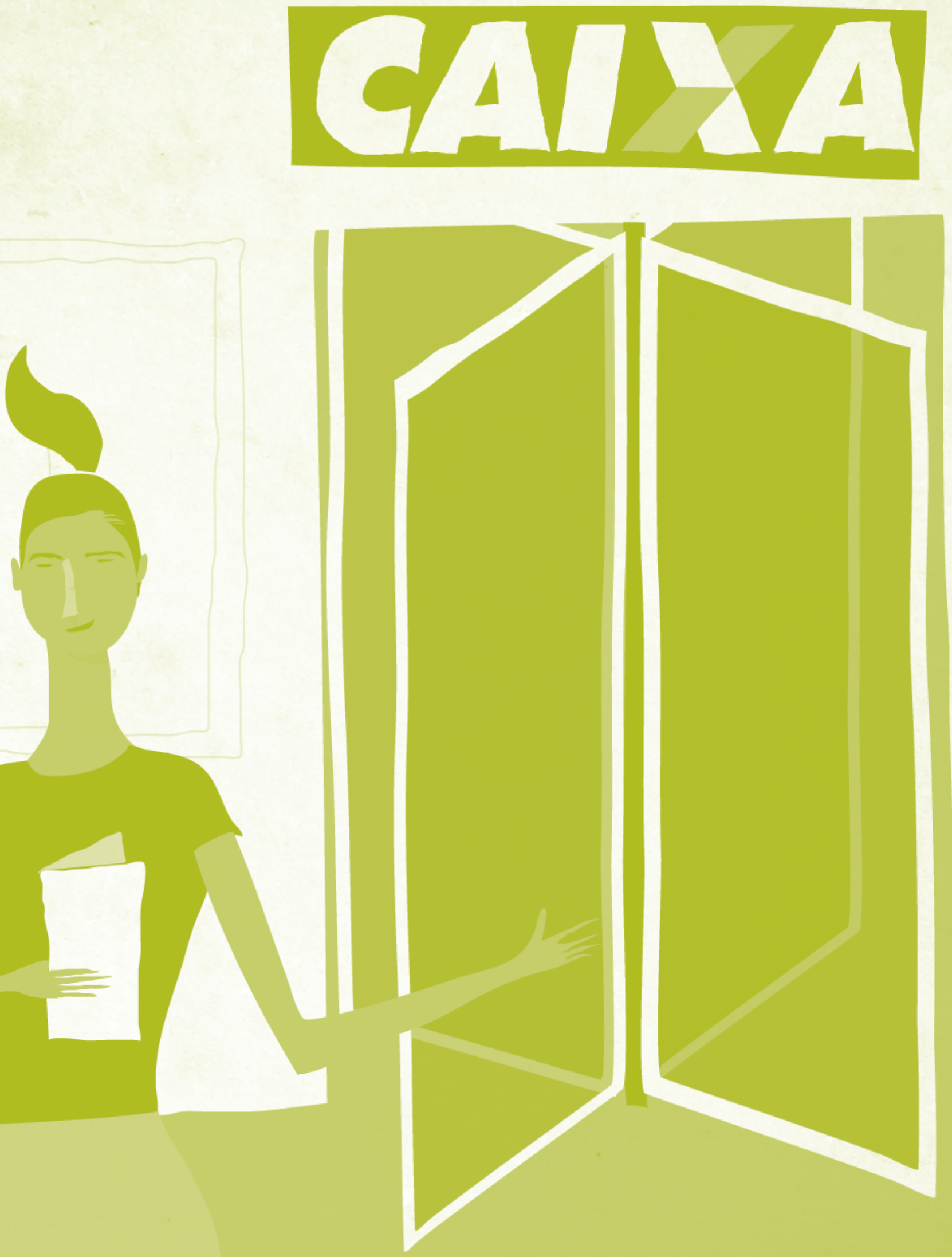


\section{A imagem institucional da Caixa Econômica Federal: opinião dos funcionários e clientes da Agência Itajaí}

João Carissimi

- Mestre em Comunicação e Informação pela Universidade Federal do Rio Grande do Sul (UFRGS)

- Especialista em Marketing pela Pontifícia Universidade Católica do Rio Grande do Sul (PUC-RS)

- Especialista em Administração em Publicidade e Propaganda e Relações Públicas pela PUC-RS

- Bacharel em Comunicação com habilitação em Relações Públicas pela Universidade de Caxias do Sul (UCS)

- Professor do curso de Graduação em Relações Públicas e da Especialização em Gestão em Comunicação Empresarial da Universidade do Vale do Itajaí (Univali)

- Professor responsável pela disciplina Monografia - modalidade Artigo Científico da Univali

- Professor pesquisador no Grupo de Pesquisa Redes de Comunicação da Univali

-vcarissimi@univali.br

Narjara Amorim

- Acadêmica da disciplina Monografia - Artigo Científico do curso de Comunicação Social com habilitação em Relações Públicas da Univali

- Estudante pesquisadora do Grupo de Pesquisa Redes de Comunicação da Univali

•narjaraamorim@yahoo.com.br 
Primeiramente, revisou-se a bibliografia que define imagem organizacional. Em um segundo momento, procurou-se descrever a identidade da Caixa Econômica Federal (CEF) por meio de pesquisa documental e virtual. Em seguida, realizou-se pesquisa de opinião junto aos 36 funcionários e 250 clientes da Agência Itajaí da CEF, com o objetivo de analisar a imagem que têm da instituição. Os resultados demonstraram identificação com a marca CEF, o que caracteriza a legitimidade da instituição, a unicidade de seu discurso e a integridade dos elementos que compõem a identidade.

PALAVRAS-CHAVE: IMAGEM • IDENTIDADE • CAIXA ECONÔMICA FEDERAL • PESQUISA DE OPINIÃO

\section{Abstract}

Preliminarily a review was carried out focused on the bibliography that defines organizational image. This was supplemented by seeking to describe the identity of the Caixa Econômica Federal (Federal Savings Bank), or CEF, by using a documental and virtual survey. Following this, an opinion survey was conducted with 36 employees and 250 clients of the CEF's branch in Itajaí, with the purpose of analyzing the institution's image. The results showed identification with the CEF brand, which characterizes the legitimacy of the institution, the uniqueness of its discourse and the integrity of the elements that make up its identity.

KEYWORDS: IMAGE • IDENTITY • CAIXA ECONÔMICA FEDERAL • OPINION SURVEY

\section{Resumen}

En primer lugar se revisó la bibliografía que define la imagen organizativa. En un segundo momento se buscó describir la identidad de la Caixa Econômica Federal (CEF) por medio de una investigación documental y virtual. Luego se realizó una investigación de opinión con los 36 empleados y los 250 clientes de la Agencia Itajaí de la CEF, con el objetivo de analizar la imagen que tienen de la institución. Los resultados demostraron identificación con la marca CEF, lo que caracteriza la legitimidad de la institución, la unicidad de su discurso y la integridad de los elementos que componen la identidad.

PALABRAS CLAVE: IMAGEN • IDENTIDAD • CAIXA ECONÔMICA FEDERAL • INVESTIGACIÓN DE OPINIÓN 
imagem e a identidade institucional cada vez mais demonstram a sua importância como objetos de estudo para a área de Comunicação Social e, em especial, para o profissional de Relações Públicas. As instituições participam de um mercado competitivo, estabelecendo suas identidades por meio de seu discurso, pela transparência de seus atos, pela sua razão de ser, pela sua responsabilidade social e pela comercialização dos seus produtos e serviços. Esses fatores são fundamentais para a construção ou formação de uma imagem favorável, tornando-se diferenciais em relação à concorrência, na hora em que o público faz sua opção pela instituição.

Com o objetivo de compreender o fenômeno imagem institucional no segmento banco, procurou-se identificar pesquisas sobre o assunto e dados que demonstrassem alguns pontos negativos quanto ao item atendimento, traduzindo uma imagem negativa percebida pelos públicos.

Pesquisa realizada em 2007 pela Associação Nacional dos Bancos revela que um dos principais problemas dos bancos, na visão dos usuários, são as filas: $23 \%$ dos entrevistados apontam insatisfação na permanência em filas por mais de 15 minutos. Já os relatórios de processos contra bancos registrados no Procon de Itajaí, no período de fevereiro de 2006 a fevereiro de 2007 , apontam reclamações referentes a juros abusivos, permanência nas filas, lançamentos indevidos dos cartões de créditos, entre outros.

A primeira fase de trabalho foi a compreensão dos termos imagem e identidade, realizada por meio de pesquisa bibliográfica da área de Relações Públicas, entre outras áreas de conhecimento. Para melhor compreensão do tema imagem e identidade, este artigo apresenta conceitos de autores como Argenti (2006), Kunsch (2000), Las Casas (2001), Neves (1998 e 2000), Simões (1995) e Torquato (2002).

Na segunda fase do trabalho, iniciou-se um processo de auditoria de imagem, por meio de pesquisa virtual e documental, resgatando a identidade da Caixa Econômica Federal (CEF), bem como a da Agência de Itajaí e, na seqüência, foi realizada a pesquisa de opinião junto aos funcionários e clientes da CEF - Agência de Itajaí. Assim sendo, três focos de estudo foram eleitos: a identidade da CEF, a pesquisa de opinião junto aos funcionários e clientes e a imagem dos públicos entrevistados em relação à identidade divulgada.

Diante disso, o objetivo geral deste trabalho é apresentar uma análise sobre as opi- 
niões emitidas pelos funcionários e clientes da CEF - Agência Itajaí em relação à imagem da instituição. Seus objetivos específicos são compreender os conceitos de imagem e identidade, descrever a identidade da CEF e apontar sua imagem junto aos funcionários e clientes. Para tal, partiu-se da seguinte questão-problema: qual a imagem que os funcionários e clientes da Agência de Itajaí têm da CEF?

\section{Imagem e identidade}

A produção científica do campo teórico da Comunicação Organizacional, em especial das Relações Públicas, tem trazido uma forte discussão sobre o enfoque imagem institucional. Para melhor compreender o termo, é importante recorrer a alguns referenciais conceituais sobre imagem e identidade. Destaca-se que o termo imagem institucional utilizado neste texto é também identificado por muitos autores como imagem organizacional, imagem empresarial e imagem corporativa.

A imagem é o reflexo da identidade de uma organização ${ }^{1}$. Segundo Argenti (2006, p. 81), imagem institucional "é a organização sob o ponto de vista de seus diferentes públicos". Nesse sentido, uma instituição pode ter diversas imagens, dependendo dos públicos com os quais está interagindo. Em outras palavras, imagem não é realidade. "Imagem é percepção da realidade pela pessoa", como afirma Simões (1995, p. 201). Assim, compreendendo a imagem institucional com base na percepção dos públicos, será possível avaliar a identidade ao poder conhecer profundamente o que a instituição é, faz, diz ser, e para onde ela está posicionada.

A história da imagem institucional desenvolveu-se no século XX, com a expansão da atividade comercial e empresarial. Já naquela época, comerciantes e empresários tinham uma imagem negativa frente aos seus clientes, que os viam como aqueles que só pensavam nos lucros das vendas. Segundo Neves (2000, p. 20):

"[...] como o público claramente identificado pelo empresário, comerciante etc., só existia o cliente. Essa era a única entidade que requeria a atenção do homem de negócios, era com ele-e apenas com ele-que um esforço de comunicação se justificava. Entretanto, já nessa época, a fama do comerciante não era boa. Já tinha imagem de vigarista. Para os clientes, o comerciante roubava no troco, no peso, vendia alimento estragado, explorava empregados, fazia propaganda enganosa, só pensava em lucrar etc. E essa forma não estava restrita ao pequeno empresário. Grandes magnatas tinham imagem ainda pior."

No século XXI não é diferente, pois muitos empresários continuam acreditando que

10 termo "organizações" é utilizado, de forma ampla, para identificar empresas privadas, públicas, governamentais, associações civis e organizações não-governamentais. Porém, por se tratar de uma organização do sistema bancário governamental, Caixa Econômica Federal, objeto de estudo da pesquisa, usaremos sempre o termo "instituição". 
a comunicação tem um caráter exclusivo de vender para o cliente seu produto ou serviço, não considerando outros públicos, tais como: fornecedor, investidor, líder de opinião, funcionário, entre outros. Sendo assim, muitas instituições pensam nos lucros de suas vendas e não se dão conta da importância que uma imagem positiva representa no espaço dos relacionamentos estabelecidos pela Comunicação Institucional com os seus diversos públicos.

A imagem de uma instituição é a visão que os públicos têm a seu respeito e como ela é percebida. "Consideramos aqui a imagem como o conjunto de representações mentais criado pelo público em relação a uma empresa ou instituição" (LAS CASAS, 2001, p. 48). Essas representações estão na mente das pessoas, o que elas lembram de uma determinada instituição, formando, assim, opiniões positivas ou negativas sobre ela. Simões (1995, p. 201) diz que é "com base na percepção da realidade e não da própria realidade que a pessoa age sobre o meio ambiente ou sobre si mesma, donde a necessidade de que essa percepção seja a mais próxima possível da realidade [...]".

Por exemplo, sobre as instituições financeiras, como os bancos, algumas pessoas têm em sua mente a lembrança de filas, juros abusivos, pagamentos de suas despesas, a segurança de seu dinheiro e o bom atendimento. Esses seriam alguns dos elementos que podem formar uma imagem institucional. Entre outros, considerem-se o prédio, a infra-estrutura, os recursos humanos, a publicidade, as ações de patrocínio e de responsabilidade social, a divulgação de tarifas, a divulgação do rendimento da poupança, as mensagens institucionais.

Com base nas mensagens e discursos proferidos pelas instituições, desde um simples e-mail até as campanhas institucionais de propaganda, as pessoas podem desenvolver uma imagem frente às suas ações de caráter positivo, no sentido de elogiar a instituição para outros públicos, estabelecer relações de parceria, adquirir produtos e serviços, recomendar a instituição, entre outros. Com isso, a imagem institucional contribui significativamente para o posicionamento da instituição entre os públicos, determinando, assim, a sua solidez no mercado.

"[...] Imagem pode alavancar e decidir negócios, ganhar eleições, potencializar qualidades e virtudes, suprir deficiências, fazer a diferença, encurtar caminhos, aumentar a produtividade, dar de comer a egos famintos, em suma, fazer a vida mais fácil, agradável e lucrativa." (NEVES, 1998, p. 17)

No entanto, quando o público forma uma imagem negativa da instituição, o que pode se dar pela falta de entendimento da mensagem institucional, por exemplo, ou quando os serviços não estão disponíveis no acesso ao terminal, quando se perde um tempo considerável em uma enorme fila ao pagar contas, ou até mesmo quando se relaciona os altos ganhos dos bancos com o investimento na área social, dá-se margem a uma defasagem entre o que a instituição é, ou diz ser, e aquilo que o cliente 
percebe. Nesse sentido, a imagem negativa pode enfraquecer os negócios da instituição em relação às suas metas e desempenho.

Considerando que uma imagem favorável é um fator decisivo em relação à concorrência e ao sucesso de uma instituição, é importante destacar que vários são os fatores responsáveis pela formação de uma imagem positiva. Exemplo disso são as pessoas que trabalham na instituição, a estrutura física, como as instalações, a decoração, os móveis e o sistema a ela pertencentes.

O bom atendimento dado pelos funcionários e o conforto da agência são fundamentais para a obtenção de uma imagem positiva de uma instituição bancária. Além desses fatores, o cliente também espera rapidez e agilidade no atendimento, ainda mais em função das tecnologias disponíveis em qualquer lugar, ou no momento em que busca dados sobre a sua conta junto ao banco.

Uma imagem institucional favorável envolve muito mais que uma bela decoração ou funcionários simpáticos: envolve comportamentos da instituição. De acordo com Kunsch (2003, p. 171):

"A imagem representa o que está na cabeça do público a respeito do comportamento institucional das organizações e dos seus integrantes, qual é a imagem pública, interna, comercial e financeira que passa pela mente dos públicos e da opinião pública sobre as mesmas organizações."

No Brasil, esse enfoque ganhou força depois de vários escândalos envolvendo dirigentes de instituições, pois estão diretamente relacionados ao conceito que se tem das organizações em que atuam. Portanto, toda atitude pessoal e/ ou profissional adotada pelo dirigente da instituição e relacionada ao campo da ética empresarial afeta diretamente a imagem institucional e, assim, pode ocasionar a formação de uma imagem pública negativa, ainda mais em se tratando de uma instituição pública.

Trabalhar com a questão da identidade é o primeiro passo em busca de uma imagem institucional. Por essa razão, é fundamental analisar todos os fatores relacionados à identidade da instituição, tais como: o histórico, as filosofias, os produtos e serviços, o ambiente interno, os funcionários, os diretores, os produtos e serviços, a comunicação, entre outros.

Por identidade deve-se entender aquilo que realmente a instituição é, seu caráter, sua personalidade, suas atitudes e valores. A identidade envolve um conjunto de elementos por intermédio dos quais a opinião pública forma uma imagem da organização.

"[...] a história da empresa, seus produtos e serviços, comportamentos de seus dirigentes, a atitude profissional dos empregados, a propaganda, a programação visual, as cores, a arquitetura dos prédios, o desenho dos escritórios, os eventos que realiza, os programas sociais e culturais que patrocina, como se relaciona com os diferentes públicos 
etc. É esse conjunto de elementos - objetivos visuais e simbólicos - que sustenta a imagem da empresa, fortalecendo os atributos positivos." (NEVES, 2000, p. 31)

A realidade de uma instituição está diretamente ligada à sua identidade. A exposição do nome ou logomarca nos produtos, serviços, peças e brindes da instituição é um fator que retrata sua identidade, o que podemos chamar de identidade visual.

"A identidade [visual] de uma empresa é a manifestação visual de sua realidade, conforme transmitida através do nome, logomarca, lema, produtos, serviços, instalações, folheteria, uniformes e todas as outras peças que possam ser exibidas, criadas pela organização e comunicadas a uma grande variedade de públicos." (ARGENTI, 2006, p. 80)

Por meio de sua identidade e dos vários tipos de contato que os públicos têm com ela, uma organização gera a sua imagem pública. Para Torquato (2002, p. 104), "a identidade se projeta na imagem”. Sendo assim, se a organização quer gerar uma imagem consistente, que mantenha seus atributos essenciais para todos os públicos, sua identidade deverá ser consistente. Mesmo assim, pequenas diferenças no detalhe do conjunto de atributos que formam a imagem de uma organização podem ser projetadas, para os diferentes públicos de interesse (ex.: clientes, mercado financeiro, fornecedores), conforme seja conveniente.

A identidade tem grande importância na construção de uma imagem. Cabe ao profissional de Relações Públicas, pela investigação da identidade institucional, que pode ocorrer por meio de diagnóstico organizacional, pesquisa de opinião, auditoria de imagem, auditoria interna, auditoria da Comunicação Organizacional, entre outras técnicas, trabalhá-la sempre com a finalidade de orientar e gerenciar o planejamento estratégico de comunicação, com o objetivo principal de comparar a imagem desejada com a real.

Evidentemente, ao identificar a identidade institucional, o relações-públicas pode verificar o que a organização faz, diz ser, demonstra em suas propostas institucionais, comerciais, ou até na relação com seu público interno, possibilitando, assim, criar indicadores que serão norteadores para uma pesquisa junto aos seus públicos estratégicos. Com isso, auferirá a imagem institucional percebida pelos públicos em suas várias posições frente à organização, uma vez que o público identifica a organização pelo seu discurso, pela ética organizacional, pela comercialização de seus produtos e serviços, pela postura de seus dirigentes, pela condução dos seus negócios frente aos problemas sociais, culturais e ecológicos, entre outros.

Tais fatores são determinantes para a captação e a manutenção dos clientes e na aplicação de recursos e retorno dos investimentos, na postura frente a alguma crise que envolva a organização, na escolha de seus produtos e serviços em virtude da con- 
corrência, na opção pela instituição no caso de doação ou ações de voluntariado, na expressão do sentimento manifestado em qualquer lugar ou momento a favor da organização, na defesa dos direitos e deveres da organização, entre tantos outros motivos.

\section{Pesquisa}

Para descrever brevemente a identidade da instituição pesquisada, partiu-se de uma pesquisa virtual, baseada no site da CEF, bem como de uma pesquisa documental realizada em atas, catálogos, folder e jornais cedidos pela gerente geral da CEF - Agência de Itajaí.

Pela natureza da pesquisa aplicada, identificou-se a técnica de pesquisa de opinião como a mais apropriada para a investigação da imagem da CEF. Optou-se, então, por dois públicos da agência da CEF de Itajaí: funcionários e clientes.

Foram elaborados dois tipos de instrumentos de coleta de dados, sendo o primeiro qualitativo, destinado aos funcionários, e o segundo quantitativo, aplicado aos clientes, considerando-se o universo e a amostra da pesquisa. Apresentado o modelo à gerência geral da agência, solicitaram-se dados sobre os funcionários e clientes, bem como autorização para aplicação da pesquisa e a assinatura do Termo de Livre Consentimento. Antes da aplicação da pesquisa de opinião, os questionários foram submetidos a um pré-teste. Todo o processo de tabulação foi manual. A geração de planilhas no Excel permitiu a apresentação de gráficos.

\section{Identidade da Caixa Econômica Federal}

A história da CEF teve início no dia 12 de janeiro de 1861, quando Dom Pedro II, com o propósito de incentivar a poupança e de conceder empréstimos sob penhor, deu origem à CEF. Presenciando transformações que marcaram a história do Brasil, a CEF acompanhou mudanças de regimes políticos e participou ativamente do processo de urbanização e industrialização do país.

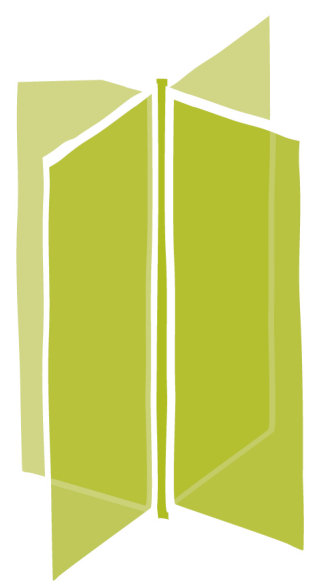


A CEF estabeleceu estreitas relações com a população, assistindo suas necessidades imediatas por meio de poupança, empréstimos, FGTS, PIS, seguro desemprego, crédito educativo, financiamento habitacional e transferência de benefícios sociais. Também criou as Loterias Federais, das quais detém o monopólio desde 1961.

Uma instituição $100 \%$ pública, a CEF atende não só aos seus clientes, mas a todos os trabalhadores formais do Brasil, por meio do pagamento de FGTS, PIS e seguro desemprego, e a beneficiários de programas sociais. É o maior banco público da América Latina. Sua base de clientes foi expandida em $42 \%$ nos últimos dois anos e meio, subindo de 23,1 milhões para 33,6 milhões de pessoas. Isso representa quase $60 \%$ da captação de todo o mercado, tratando-se de poupança.

A CEF oferece a maior rede de atendimento do país, abrangendo todos os $5.561 \mathrm{mu}$ nicípios brasileiros, com mais de 17 mil pontos de atendimento entre agências e lotéricas.

Sendo uma instituição financeira, a CEF tem como objetivo promover a inclusão social e, para que isso se torne realidade, apóia iniciativas artístico-culturais, educacionais e desportivas.

São princípios organizacionais da CEF (CAIXA ECONÔMICA FEDERAL, 2007):

\section{Missão}

Promover a melhoria contínua da qualidade de vida da sociedade, intermediando recursos e negócios financeiros de qualquer natureza, atuando, prioritariamente, no fomento ao desenvolvimento urbano e nos segmentos de habitação, saneamento e infra-estrutura, e na administração de fundos, programas e serviços de caráter social.

\section{Visão}

- A CAIXA será referência mundial como banco público integrado, rentável, socialmente responsável, eficiente, ágil e com permanente capacidade de renovação.

- Manterá a liderança na implementação de políticas públicas e será parceira estratégica dos governos estaduais e municipais.

- Consolidará sua posição como o banco da maioria da população brasileira, com relevante presença no segmento de pessoa jurídica e excelente relacionamento com seus clientes.

- Será detentora de alta tecnologia da informação em todos os canais de atendimento e se destacará na gestão de pessoas, reconhecidas em seu mérito, capacitadas e com desenvolvido espírito público.

- Manterá relacionamentos sólidos, coesos e inovadores com parceiros competentes e de forte compromisso social. 


\section{Valores}

- Direcionamento de ações para o atendimento às expectativas da sociedade e clientes.

- Busca permanente de excelência na qualidade de serviços.

- Equilíbrio financeiro em todos os negócios.

- Conduta ética pautada exclusivamente nos valores da sociedade.

- Respeito e valorização do ser humano.

A comunicação da CEF é dirigida por uma agência central que está localizada em Brasília, conhecida como Sumai (Superintendência Nacional de Marketing e Relações Institucionais).

Todas as políticas de comunicação, elaboração de folders, propagandas e patrocínio são dirigidas pela Sumai, que as repassa para as demais agências da CEF. A CEF mantém como padrão a exibição da sua logomarca em todos os seus serviços, instrumentos de comunicação e brindes tais como: calendário, caneta, camiseta, fachada, folder, boné, porta-caneta, banner, entre outros.

\section{Figura 1}

\section{Logomarca da CEF - identidade visual}

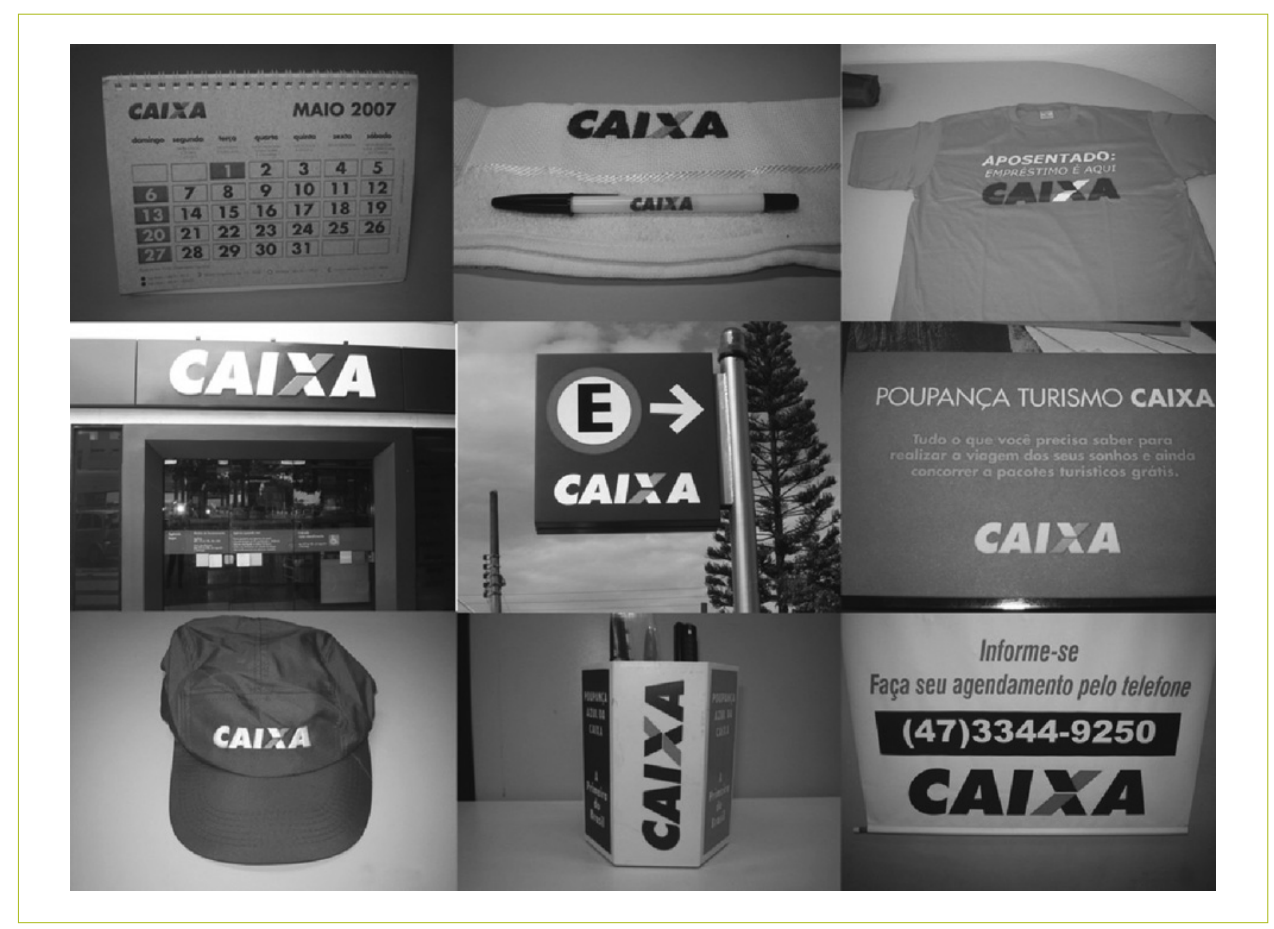

Fonte: Elaborado pelos autores 


\section{Caixa Econômica Federal - Agência Itajaí}

A CEF - Agência Itajaí - iniciou suas atividades em 22 de maio de 1946, na Rua Lauro Muller, $\mathrm{n}^{\circ}$ 50, na cidade de Itajaí, SC. Em novembro de 1982, mudou-se para outro prédio, localizado também na Rua Lauro Muller, $\mathrm{n}^{\circ} 73$, onde funciona até hoje.

$\mathrm{Na}$ inauguração estiveram presentes o Governador Antônio Carlos Konder Reis, o Presidente da CEF, Gil Maciera, e algumas autoridades locais. Também foram convidados os clientes mais antigos da CEF, sendo que alguns foram homenageados. Na época, comentava-se que a agência era muito ampla, comparando-se com os demais bancos da região.

Em 1995, a Agência Itajaí já não comportava a quantidade de clientes e empregados que nela trabalham. Por esse motivo, foi realizada uma reforma na área interna e no estacionamento, tudo para melhor atender aos seus clientes.

A cidade de Itajaí também conta com outra agência da CEF, localizada na Rua Indaial, $\mathrm{n}^{\circ} 1700$, no bairro São João, conhecida como Agência Cidade do Porto.

\section{Pesquisa com os funcionários}

Identificou-se o universo de 40 funcionários, na Agência Itajaí, entre gerentes e técnicos bancários. A pesquisa de opinião foi realizada em abril de 2007, no período das 9 às 17 horas. Foram entregues 36 questionários. O critério estabelecido para a aplicação da pesquisa com todos os funcionários foi o de estarem presentes no dia. O instrumento de coleta de dados obtinha seis questões abertas e perfil.

Em relação ao perfil dos entrevistados, $53 \%$ eram do sexo feminino e $47 \%$ do sexo masculino; quanto à idade dos entrevistados, 69\% tinham mais de 40 anos; $17 \%$, de 31 a 40 anos; e $14 \%$, de 21 a 30 anos. Questionados sobre há quanto tempo são funcionários da CEF - Agência Itajaí, constatou-se que 44\% trabalham há menos de 5 anos; $25 \%$, de 11 a 20 anos; $17 \%$, de 6 a 10 anos; e $14 \%$, há mais de 20 anos.

Para a tabulação dos resultados, todos os questionários foram numerados de 1 a 36, não identificando o entrevistado. As questões submetidas aos respondentes estão descritas no Quadro 1. Apresentam-se os resultados no Quadro 1 de duas maneiras: a primeira, como respostas gerais, classificadas como a maioria e, na segunda, selecionaram-se entre todos os entrevistados duas respostas mais representativas para cada pergunta. 


\section{Resultados}

\section{Quadro 1}

Imagem e identidade da Caixa Econômica Federal

\begin{tabular}{|c|c|c|c|}
\hline Pergunta & Respostas gerais & $\begin{array}{c}\text { Resposta do } \\
\text { questionário } \mathrm{n}^{\circ} 8\end{array}$ & $\begin{array}{c}\text { Resposta do } \\
\text { questionário } n^{\circ} 21\end{array}$ \\
\hline $\begin{array}{c}\text { 1. } 0 \text { nome Caixa } \\
\text { Econômica Federal } \\
\text { lembra...? }\end{array}$ & $\begin{array}{c}\text { Poupança e } \\
\text { habitação }\end{array}$ & $\begin{array}{c}\text { "Casa própria, PIS, } \\
\text { lotérica, Mega Sena, } \\
\text { poupança e cheque } \\
\text { azul" }\end{array}$ & $\begin{array}{l}\text { "Solidez, tradição, } \\
\text { confiança, habitação, } \\
\text { poupança etc." }\end{array}$ \\
\hline Pergunta & Respostas gerais & $\begin{array}{c}\text { Resposta do } \\
\text { questionário } \mathrm{n}^{\circ} 20\end{array}$ & $\begin{array}{c}\text { Resposta do } \\
\text { questionário n } 33\end{array}$ \\
\hline $\begin{array}{l}\text { 2. Qual o slogan } \\
\text { da CEF? }\end{array}$ & $\begin{array}{l}\text { "Vem pra Caixa } \\
\text { você também” e } \\
\text { “Vem pra Caixa" }\end{array}$ & $\begin{array}{c}\text { “Caixa para você e } \\
\text { para todos os } \\
\text { brasileiros” }\end{array}$ & $\begin{array}{l}\text { "Vem pra caixa você } \\
\text { também! Vem" }\end{array}$ \\
\hline Pergunta & Respostas gerais & $\begin{array}{c}\text { Resposta do } \\
\text { questionário } n^{\circ} 4\end{array}$ & $\begin{array}{c}\text { Resposta do } \\
\text { questionário }{ }^{\circ} 28\end{array}$ \\
\hline $\begin{array}{l}\text { 3. } 0 \text { que a CEF está } \\
\text { divulgando na mídia? }\end{array}$ & $\begin{array}{c}\text { Poupançudos e } \\
\text { Jogos Pan } \\
\text {-americanos }\end{array}$ & $\begin{array}{c}\text { "Caixa, a } \\
\text { patrocinadora do Pan } \\
\text { do Brasil" }\end{array}$ & $\begin{array}{l}\text { "Incentivo à poupança } \\
\text { com os Poupançudos e } \\
\text { patrocinadora oficial } \\
\text { do atletismo no Pan" }\end{array}$ \\
\hline Pergunta & Respostas gerais & $\begin{array}{c}\text { Resposta do } \\
\text { questionário } n^{\circ} 5\end{array}$ & $\begin{array}{c}\text { Resposta do } \\
\text { questionário }{ }^{\circ} 11\end{array}$ \\
\hline $\begin{array}{l}\text { 4. Qual a sua opinião } \\
\text { sobre o atendimento da } \\
\text { CEF - Agência Itajaí } \\
\text { aos seus clientes? }\end{array}$ & Ótimo e bom & $\begin{array}{l}\text { “Os clientes são } \\
\text { atendidos da melhor } \\
\text { forma possível, de } \\
\text { maneira cortês sempre } \\
\text { buscando soluções } \\
\text { para seus problemas" }\end{array}$ & $\begin{array}{l}\text { “0 atendimento ao } \\
\text { cliente está voltado } \\
\text { para a solução de seus } \\
\text { problemas, o cliente } \\
\text { sempre tem razão, este } \\
\text { lema é seguido } \\
\text { diariamente" }\end{array}$ \\
\hline Pergunta & Respostas gerais & $\begin{array}{c}\text { Resposta do } \\
\text { questionário n } 29\end{array}$ & $\begin{array}{c}\text { Resposta do } \\
\text { questionário } \mathrm{n}^{\circ} 36\end{array}$ \\
\hline $\begin{array}{l}\text { 5. } 0 \text { que você acha que } \\
\text { o cliente fala da CEF? }\end{array}$ & Fala muito bem & $\begin{array}{l}\text { "Fala bem, sempre } \\
\text { escuto elogios" }\end{array}$ & $\begin{array}{l}\text { "O cliente fala bem, } \\
\text { estando satisfeito com } \\
\text { o atendimento } \\
\text { recebido" }\end{array}$ \\
\hline Pergunta & Respostas gerais & $\begin{array}{c}\text { Resposta do } \\
\text { questionário nº } 3\end{array}$ & $\begin{array}{c}\text { Resposta do } \\
\text { questionário n } 18\end{array}$ \\
\hline $\begin{array}{l}\text { 6. Qual a sua opinião } \\
\text { sobre a imagem } \\
\text { institucional da CEF? }\end{array}$ & $\begin{array}{l}\text { Positiva, ótima } \\
\text { e boa }\end{array}$ & $\begin{array}{c}\text { "A imagem da Caixa } \\
\text { está ligada ao } \\
\text { governo" }\end{array}$ & $\begin{array}{l}\text { "É um banco com uma } \\
\text { ótima imagem, por } \\
\text { transmitir confiabilidade } \\
\text { e segurança" }\end{array}$ \\
\hline
\end{tabular}

Fonte: Tratamento dos dados 


\section{Pesquisa com os clientes}

Partindo do universo de 37 mil clientes cadastrados na CEF - Agência Itajaí, definiuse como amostra 380 , e margem de erro de $3 \%$. A pesquisa foi realizada nos dias 15 e 16 de maio de 2007 , tendo início a partir das $10 \mathrm{~h}$ e término às $16 \mathrm{~h} 30 \mathrm{~min}$, aplicada pela pesquisadora e funcionários terceirizados.

Foram entregues 380 questionários, retornando 311 (81,84\%) respondidos, sendo que $61(19,64 \%)$ dos questionários foram anulados, pois estavam irregulares por apresentarem respostas múltiplas e rasuradas. Como amostra da pesquisa, utilizaram-se 250 $(80,38 \%)$ questionários para a tabulação. O instrumento de coleta de dados tinha sete questões fechadas, apresentadas nos Gráficos 1, 2, 3, 4, 5 e 6, e no Quadro 2.

Em relação ao perfil dos entrevistados, $59 \%$ eram do sexo feminino e $41 \%$ do sexo masculino. Questionados sobre a idade, constatou-se que $44 \%$ tinham entre 18 e 30 anos; $28 \%$, entre 31 e 40 anos; e $28 \%$, com mais de 40 anos. Em relação a quanto tempo os entrevistados eram clientes da agência, 48\% eram clientes há menos de 5 anos; 29\%, entre 6 e 10 anos; $15 \%$, entre 11 e 20 anos, e $8 \%$, há mais de 20 anos.

\section{Resultados}

Ao serem questionados sobre o que o nome Caixa Econômica Federal lembra, foram obtidos os seguintes resultados: $37 \%$ dos clientes entrevistados o relacionaram à poupança; $22 \%$, à habitação; $12 \%$, ao FGTS; $8 \%$, à loteria; $7 \%$, ao PIS / Pasep; $6 \%$, a empréstimo; $4 \%$, ao seguro desemprego; e $4 \%$, a alternativas como: governo, conta bancária, conta corrente e banco do povo (Gráfico 1).

\section{Gráfico1}

\section{Nome da CEF}

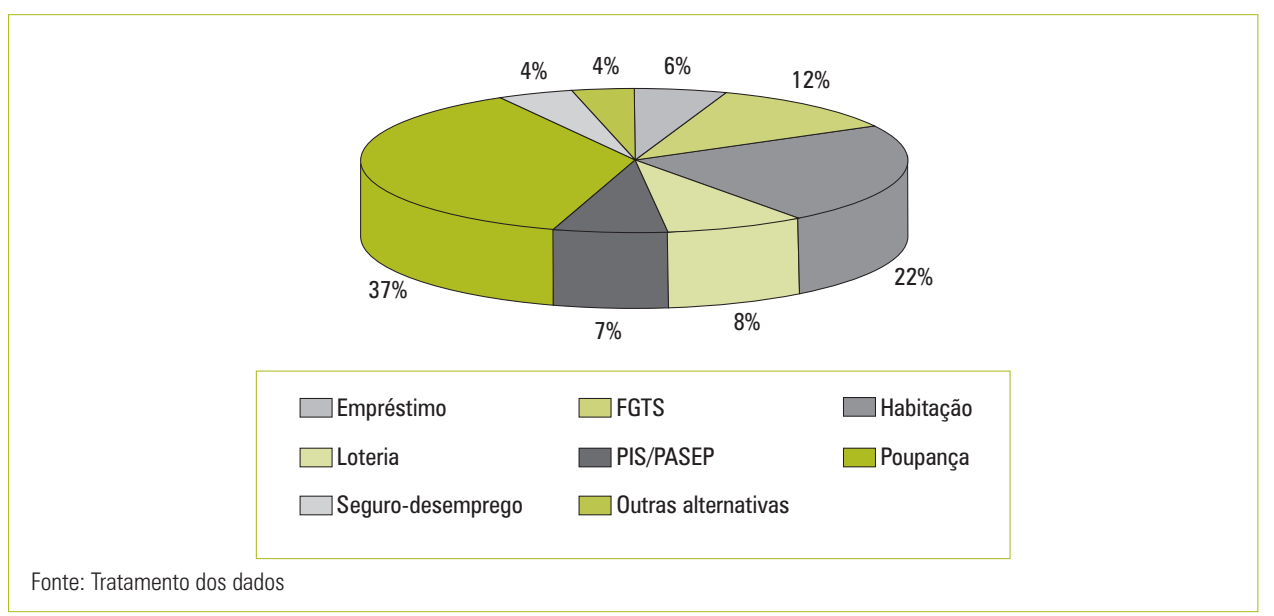


Em relação aos atributos tradição, confiança, solidez, credibilidade, ética e segurança associados à CEF, os clientes deveriam atribuir uma nota de 0 a 10 para cada item, espontaneamente, no questionário. Apresenta-se a classificação dos atributos conforme Quadro 2.

\section{Quadro 2}

\section{Atributos da CEF}

\begin{tabular}{|l|c|c|}
\hline Atributos & Pontuação & Classificação \\
\hline Tradição & 2.352 & $1^{\circ}$ lugar \\
\hline Confiança & 2.299 & $2^{\circ}$ lugar \\
\hline Solidez & 2.214 & $3^{\circ}$ lugar \\
\hline Credibilidade & 2.188 & $4^{\circ}$ lugar \\
\hline Ética & 2.172 & $5^{\circ}$ lugar \\
\hline Segurança & 2.130 & $6^{\circ}$ lugar \\
\hline
\end{tabular}

Fonte: Tratamento dos dados

Questionados sobre que banco a CEF é, 29\% dos clientes entrevistados acreditam ser um banco público; $26 \%$, um banco do povo brasileiro; $21 \%$, um banco popular; $12 \%$, o banco do trabalhador; 7\%, um banco comercial; e 5\%, um banco privado. Apresentase a identidade da CEF no Gráfico 2.

\section{Gráfico 2}

\section{Identidade da CEF}

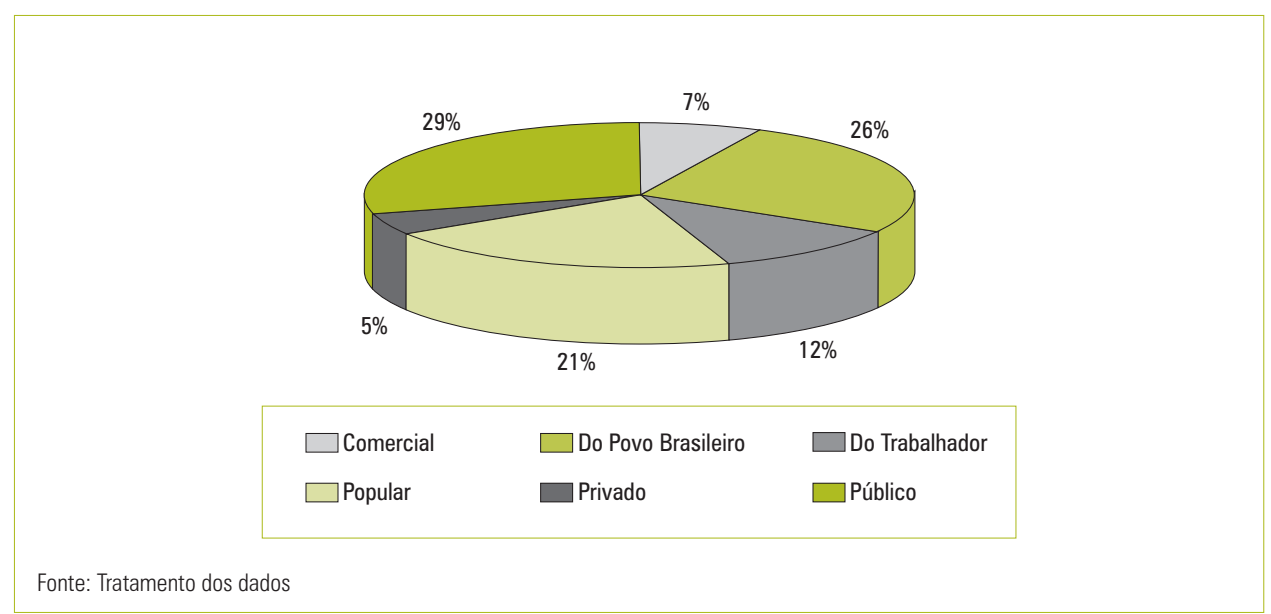

Ao serem questionados sobre o que a CEF está divulgando na mídia, 48\% afirmaram ser a Poupança da Caixa "Poupançudos"; 43\% afirmaram ser os Jogos Pan-america- 
A IMAGEM INSTITUCIONAL DA CAIXA ECONÔMICA FEDERAL: OPINIÃO DOS FUNCIONÁRIOS E CLIENTES DA AGÊNCIA ITAJAÍ •

JOÄO CARISSIMI • NARJARA AMORIM

nos; $7 \%$ afirmaram ser o FIES - financiamento estudantil; e 2\% citaram outras alternativas como casa própria e habitação (Gráfico 3).

\section{Gráfico 3}

Divulgação na mídia

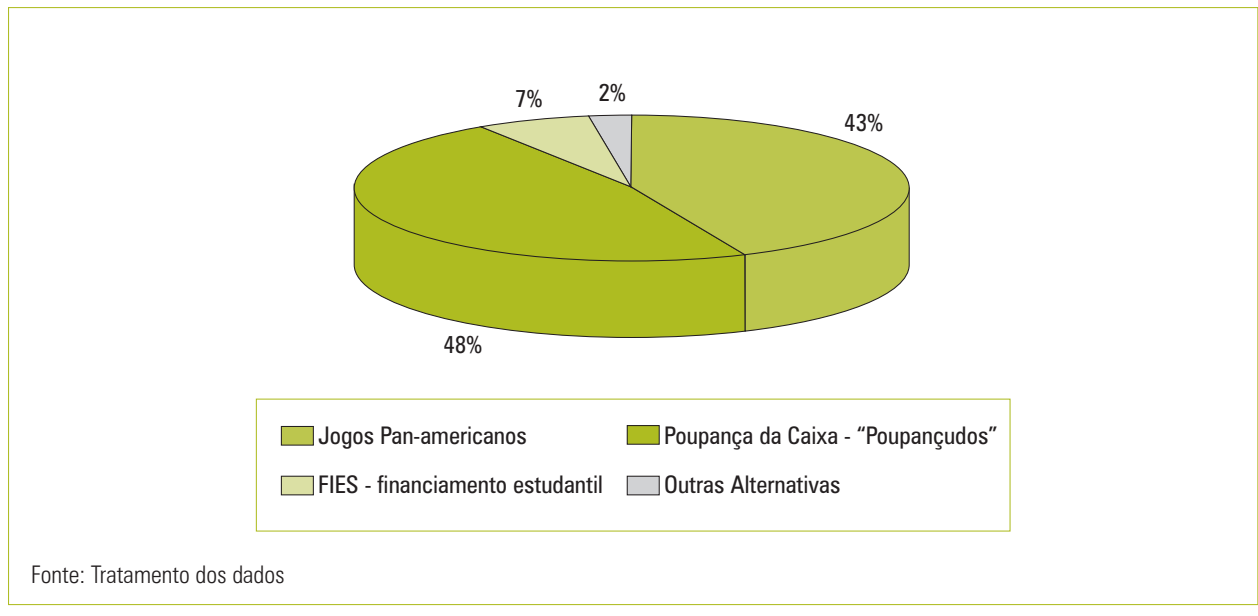

Para 45\% dos clientes entrevistados, o atendimento da CEF - Agência Itajá é bom; para $40 \%$ é ótimo; $14 \%$ disseram ser regular e, para $1 \%$, é ruim. Apresenta-se o atendimento da CEF no Gráfico 4.

\section{Gráfico 4}

\section{Atendimento da CEF}
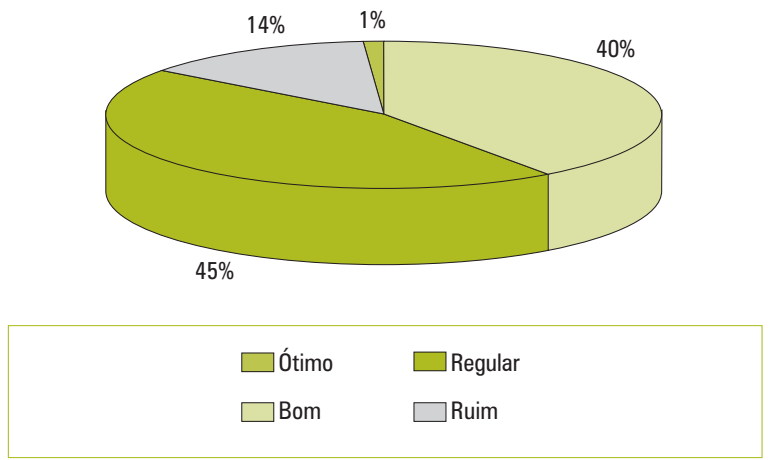

Fonte: Tratamento dos dados 
Ao serem questionados se a CEF - Agência Itajaí segue a lei dos 15 minutos em espera nas filas, $57 \%$ afirmaram que sim e $43 \%$ afirmaram que não. Apresenta-se o resultado sobre a espera nas filas no Gráfico 5.

\section{Gráfico 5}

\section{Espera nas filas}
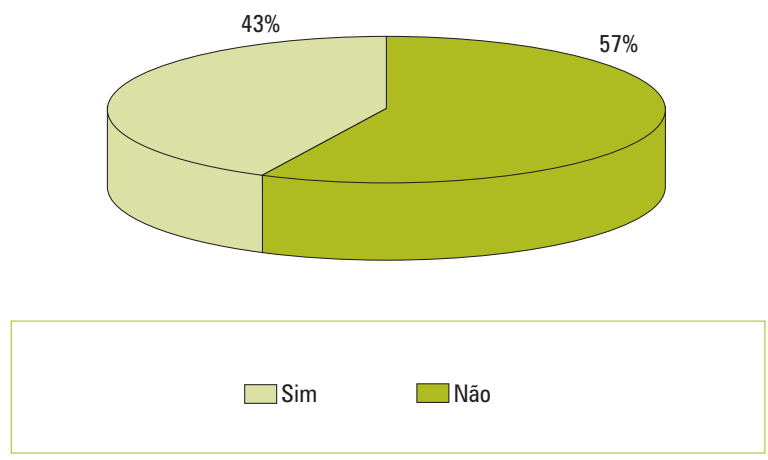

Fonte: Tratamento dos dados

Quando questionados sobre a imagem institucional da CEF, 58\% dos clientes entrevistados afirmaram ser boa, $41 \%$ afirmaram ser ótima e 3\%, regular. Apresenta-se a imagem da CEF no Gráfico 6.

\section{Gráfico 6}

\section{Imagem da CEF}
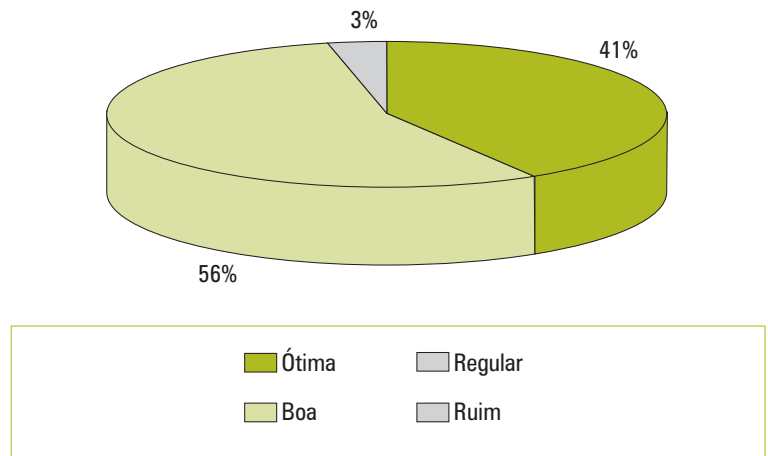

Fonte: Tratamento dos dados 


\section{Análise integrada dos resultados}

A pesquisa de opinião com os funcionários e clientes constatou que, ao serem questionados sobre o que o nome Caixa Econômica Federal lembra, as respostas gerais dos funcionários e a maioria dos clientes associam o nome da instituição à poupança e à habitação. Esses são os principais serviços oferecidos pela CEF. Conforme as informações no site da CEF, a instituição detém quase $60 \%$ da captação de todo o mercado financeiro em se tratando de poupança.

Pode-se atribuir a associação entre poupança e o nome da CEF à propaganda institucional massiva que a instituição tem feito ao longo de sua trajetória. Outro serviço associado ao nome $\mathrm{CEF}$, identificado pelos entrevistados, refere-se à habitação. Um dos programas sociais da CEF é habitação. Em sua missão, a instituição afirma atuar prioritariamente no segmento de habitação.

Na pesquisa, os clientes atribuíram notas para alguns atributos, sendo que em primeiro lugar ficou tradição e, em segundo lugar, confiança. Em relação ao atributo tradição, pode-se referir aos 146 anos da instituição atuando como instituição financeira na prestação de serviços como: poupança, habitação, conta corrente, seguro desemprego, FGTS, penhor, entre outros. Um banco de tradição que, associado ao atributo confiança, gera credibilidade para os clientes e funcionários. Destaca-se que o atributo segurança obteve, entre todos os itens, a menor classificação, sendo que segurança é um atributo relevante na questão da credibilidade ao cliente. Esse dado ajuda a pensar na possibilidade de que o atributo segurança relaciona-se ao momento econômico brasileiro.

Questionados sobre que banco a CEF é, 29\% dos clientes afirmaram ser um banco público e $26 \%$ um banco do povo brasileiro. A CEF é uma instituição $100 \%$ pública, que atende todos os brasileiros por meio de financiamento habitacional, empréstimos, pagamento de FGTS, PIS, seguro desemprego, entre outros.

Os funcionários foram questionados sobre qual é o slogan da instituição e por meio das respostas gerais, constatou-se a lembrança de "Vem pra Caixa você também", slogan ainda utilizado pela CEF. Apenas um dos funcionários apontou o atual slogan utilizado pela instituição: "Caixa para você e para todos os brasileiros".

Questionados sobre o que a CEF está divulgando na mídia, conforme as respostas gerais dos funcionários e a grande maioria dos clientes, a instituição está divulgando a Poupança da Caixa - "os Poupançudos" e os Jogos Pan-americanos. As menções recaem, portanto, sobre as propagandas institucionais massivas divulgadas pela CEF referentes ao incentivo à poupança e ao seu patrocínio aos jogos Pan-americanos.

Os resultados obtidos por meio da pesquisa de opinião mostram que, ao serem questionados sobre o atendimento da instituição, tanto os funcionários como os clien- 
tes afirmam ser ótimo e bom. Relacionando o atendimento aos clientes, estes foram questionados sobre se a CEF segue a Lei dos 15 minutos em espera nas filas, e 57\% afirmaram que $\operatorname{sim}$, mas $43 \%$ afirmaram que não. A Caixa busca seguir a Lei dos 15 minutos em espera nas filas por meio do processo de agendamento de horário para o atendimento aos clientes. Parte dos clientes entrevistados afirmou que a CEF não segue a Lei dos 15 minutos em espera nas filas. Uma hipótese para essa afirmação deve-se ao número insuficiente de funcionários para atender à grande demanda de clientes.

Questionados sobre o que acham que os clientes falam da CEF, os funcionários, de acordo com as respostas gerais, acreditam que os clientes falam bem, de acordo com o entrevistado $\mathrm{n}^{\circ} 36$, "o cliente fala de acordo com o atendimento que recebe".

Os resultados obtidos relacionam-se ao conceito de Argenti, em que o autor afirma que a identidade de uma instituição é transmitida por meio do seu nome, logomarca, lema, produtos, serviços, entre outros, e que são divulgados aos seus públicos. Aqui, estes públicos representados pelos funcionários e clientes demonstraram, por meio dos dados obtidos com a pesquisa, uma grande identificação em relação à identidade divulgada pela instituição.

Funcionários e clientes foram questionados sobre qual é a imagem institucional da CEF e foi constatado pelas respostas gerais dos funcionários e pela maioria dos clientes que a imagem da CEF é ótima e boa, o que mostra que a instituição tem uma imagem favorável frente aos públicos pesquisados. Conforme o autor Neves, a imagem faz a diferença, potencializa as qualidades e virtudes de uma instituição.

\section{Considerações finais}

A imagem de uma instituição financeira representa grande importância no mercado competitivo, em que o público faz a escolha da instituição pelos serviços oferecidos e pela imagem transmitida por meio de ações de responsabilidade social, comportamento institucional, propaganda institucional, atendimento, entre outros fatores. Pela identidade da instituição é possível construir-se uma imagem, considerando que ambas devem estar diretamente ligadas para a obtenção de uma imagem favorável frente aos públicos.

A imagem que os funcionários e clientes da CEF - Agência Itajaí têm da CEF é positiva e está diretamente ligada à sua identidade. Atributos positivos como tradição e confiança, associados à prestação de seus serviços, como poupança e habitação, geram credibilidade. Pode-se considerar que a imagem da CEF também está relacionada aos programas sociais do governo federal, por ser instituição pública e por atender às necessidades e expectativas do trabalhador brasileiro. Considera-se também que $o$ 
bom atendimento da CEF percebido pelos entrevistados é um fator fundamental para a formação da imagem da instituição.

A imagem da CEF demonstra uma identificação do público pesquisado em relação à identidade da instituição, esta revelada pelo discurso transmitido por meio das mensagens institucionais vinculadas no site, anúncios institucionais, material de divulgação e oferta de seus serviços. Isso caracteriza a legitimidade da instituição, a sua unicidade no discurso e a integridade de todos os elementos que compõem a identidade, esses refletidos na imagem favorável constatada.

Cabe ao profissional de Relações Públicas trabalhar, com base nas estratégias de comunicação, a construção e a manutenção da imagem institucional. A imagem percebida pela opinião pública deve estar relacionada à identidade projetada pela instituição, esta elaborada por meio do planejamento estratégico.

Entender o que a imagem institucional representa é compreender o que a instituição realmente é e diz ser. A imagem deve ser entendida não só pelo profissional de Relações Públicas, mas também por todos os públicos de uma organização pública, privada ou do terceiro setor.

\section{Referências}

ARGENTI, Paul A. Comunicação empresarial: a construção da identidade, imagem e reputação. Rio de Janeiro: Elsevier, 2006.

CAIXA ECONÔMICA FEDERAL. Disponível em: <www.caixa.gov.br>. Acesso em 20 abr. 2007.

KUNSCH, Margarida Maria Krohling. Planejamento de relações públicas na comunicação integrada. 4. ed. São Paulo: Summus, 2000.

LAS CASAS, Alexandre Luzzi. Novos rumos de marketing. São Paulo: Atlas, 2001.

NEVES, Roberto de Castro. Comunicação empresarial integrada. Rio de Janeiro: Mauad, 2000.

. Imagem empresarial. Rio de Janeiro: Mauad, 1998.

SIMÕES, Roberto Porto. Relações públicas: função política. 3. ed. rev. e ampl. São Paulo: Summus, 1995.

TORQUATO, Gaudêncio. Tratado de comunicação organizacional e política. São Paulo: Pioneira, 2002. 